\title{
A Catalyst for Syndiotactic Polymerization of Styrene
}

\author{
Jianfei LiU, Jiling HuANG, Yanlong QIAN, ${ }^{\dagger}$ Fan Wang, \\ and Albert S. C. CHAN* \\ Laboratory of Organometallic Chemistry, East China University of Science and Technology, \\ Shanghai 200237, People's Republic of China \\ * Department of Applied Biology \& Chemical Technology, The Hong Kong Polytechnic University, \\ Hung Hom, Kowloon, Hong Kong
}

(Received May 31, 1996)

\section{KEY WORDS Syndiotactic Polymerization / Styrene / Titanium Catalysts / Methyl Aluminoxane /}

Since Ishihara and co-workers discovered that titanium compounds, when activated with methylaluminoxane (MAO), formed very active catalysts for the syndiotactic polymerization of styrene, ${ }^{1,2}$ syndiotactic polymerization of styrene has been the focus of polymer synthesis, ${ }^{3-10}$ due to good performance of syndiotactic polystyrene (s-PS) claimed to be comparable to that of resins like nylon 66 and poly(phenylene sulfide). ${ }^{11}$ Recent years a lot of half-sandwich titanocene compounds, including $\mathrm{CpTi}(\mathrm{OR})_{3},{ }^{12}$ and $\mathrm{IndTiCl}_{3},{ }^{13}$ have been synthesized and used to polymerize styrene.

To search for high active and high syndiospecific catalysts, we prepared a series of monocyclopentadienyl titanium dichloroalkoxides $\mathrm{CpTiCl}_{2}(\mathrm{OR})(\mathrm{R}=\mathrm{Me}, \mathrm{Et}$, $\left.\operatorname{Pr}^{\mathrm{i}}\right)^{14}$ and used these compounds with MAO to polymerize styrene.

\section{EXPERIMENTAL}

$\mathrm{CpTiCl}_{3},{ }^{14} \mathrm{CpTiCl}_{2}(\mathrm{OMe}),{ }^{15} \mathrm{CpTiCl}_{2}(\mathrm{OEt}),{ }^{14} \mathrm{CpTi}-$ $\mathrm{Cl}_{2}\left(\mathrm{OPr}^{\mathrm{i}}\right),{ }^{14}$ and $\mathrm{MAO}^{16}$ were prepared according to the literatures. ${ }^{14-17}$ Styrene was purified by washing several times with dilute $\mathrm{NaOH}$ solution, dried over anhydrous $\mathrm{CaCl}_{2}$, vacuum distillation from $\mathrm{CaH}_{2}$, and stored at $-20^{\circ} \mathrm{C}$ in darkness. Toluene was distilled from sodium and diphenyl ketone under argon just before use.

Polymerization was conducted in small ampules baked under vacuum and flushed with Ar for several times. Styrene $(2 \mathrm{ml})$, an appropriate amount of MAO in toluene $\left(0.1 \mathrm{~g} \mathrm{ml}^{-1}\right)$, and titanium compounds in toluene were sequentially injected. The mixtures were kept at $50^{\circ} \mathrm{C}$ for a certain time, then terminated with $100 \mathrm{ml}$ $10 \% \mathrm{HCl}$ in $\mathrm{EtOH}$, and dried under vacuum at $50^{\circ} \mathrm{C}$ to constant weight.

\section{RESULTS AND DISCUSSION}

$\mathrm{CpTi}(\mathrm{OR})_{3}$ is used to polymerize styrene. But pure $\mathrm{CpTi}\left(\mathrm{OPr}^{\mathrm{i}}\right)_{3}$, not attainable by vacuum distillation according to the literature, has only been obtained by tedious procedures. ${ }^{12}$ However, solid compounds, CpTi$\mathrm{Cl}_{2}(\mathrm{OR})$, were easily prepared by reaction of $\mathrm{CpTiCl}_{3}$ with $\mathrm{HOR}$ in the presence of $\mathrm{NEt}_{3}$ in high yield. ${ }^{14}$ Pure $\mathrm{CpTiCl}_{2}(\mathrm{OR})$ was conveniently obtained by recrystal-

† To whom correspondence should be addressed. lization. A literature survey indicates no such compounds have been previously used for styrene polymerization. We thus present here our results of syndiotactic polymerization of styrene with $\mathrm{CpTiCl}_{2}(\mathrm{OR}) / \mathrm{MAO}$.

The experimental results are shown in Table I. Apparently, the catalyst activity and syndiospecificity of $\mathrm{CpTiCl}_{2}(\mathrm{OR}) / \mathrm{MAO}$ were higher than those of $\mathrm{CpTiCl}_{3} /$ MAO. When $\mathrm{R}=\mathrm{Me}, \mathrm{Et}, \mathrm{Pr}^{\mathrm{i}}$, the catalytic activity of $\mathrm{CpTiCl}_{2}(\mathrm{OR}) / \mathrm{MAO}$ was about 2 fold higher than that of $\mathrm{CpTiCl}_{3}$ /MAO. However, activity of catalysts was not much affected by change of alkyl groups. But the syndiospecificity of $\mathrm{CpTiCl}_{2}(\mathrm{OR}) / \mathrm{MAO}$ was 10 percent higher than that of $\mathrm{CpTiCl}_{3}{ }^{\prime} \mathrm{MAO}$ except $\mathrm{CpTiCl}_{2}-$ $(\mathrm{OMe}) / \mathrm{MAO}$, which was slightly higher than $\mathrm{CpTiCl}_{3} /$ $\mathrm{MAO}$, demonstrating the steric effect of ligands to play an important role in determining the syndiospecificity of catalysts. Evidently, more sterically hindered ligands yield more syndiospecific catalysts. We attempted to synthesize $\mathrm{CpTiCl}_{2}\left(\mathrm{OBu}^{t}\right)$ and failed to get a pure product. An impure sample was about 5 fold more active than $\mathrm{CpTiCl}_{3}$ at a syndiospecificity of $97.5 \%$ when used to catalyze the syndiotactic polymerization of styrene with MAO.

Figure 1 shows the carbon-13 NMR spectrum of the phenyl C-1 of polystyrene measured in 1,2,4-trichlorobenzene at $50^{\circ} \mathrm{C}$ with a Gemini- $300 \mathrm{MHz}$ spectrometer. This spectrum is in accordance with Ishihara's report though the solubility of our sample is poor at $50^{\circ} \mathrm{C}$. Apparently, our sample (2-butanone insoluble) is syndiotactic polystyrene.

James C. W. Chien found that hydrotitanium(III) is the syndiospecific species in styrene polymerization catalyzed by $\mathrm{CpTi}(\mathrm{OBu})_{3} / \mathrm{MAO}^{8}{ }^{8}$ We believe that in our catalytic system $\mathrm{CpTi}(\mathrm{OR}) \mathrm{H}$ may be the precursor of active site. ${ }^{18}$ Thus the $\mathrm{R}$ groups may have considerable influence on syndiospecificity. As for the activity dif-

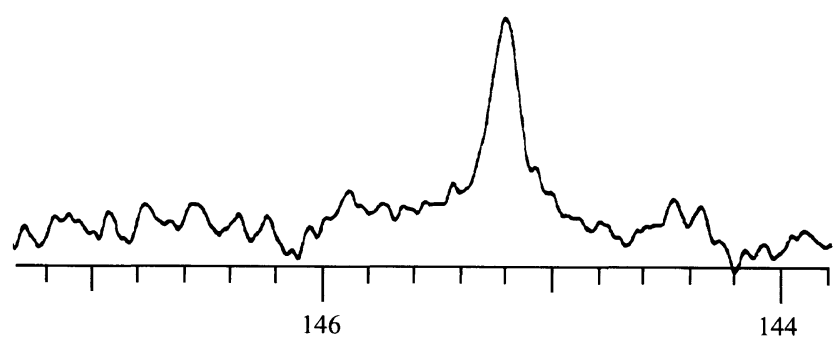

Figure 1. Carbon-13 NMR spectrum of polystyrene. 
ferences between $\mathrm{CpTiCl}_{2}(\mathrm{OR})$ and $\mathrm{CpTiCl}_{3}$, we believe that reduction of $\mathrm{CpTiCl}_{2}(\mathrm{OR})$ by $\mathrm{MAO}$ to $\mathrm{Ti}(\mathrm{III})$ may be faster and easier than the reduction of $\mathrm{CpTiCl}_{3}$ by MAO. In fact, we found that the polymerization reaction catalyzed by $\mathrm{CpTiCl}_{2}(\mathrm{OR})$ was completed sooner than the polymerization reaction catalyzed by $\mathrm{CpTiCl}_{3}$ (see Table I).

Acknowledgments. This project was supported by the China Postdoctoral Science Foundation, National Natural Science Foundation of China, and State Key Laboratory of Coordination Chemistry, Nanjing University.

Table I. Styrene polymerization by $\mathrm{CpTiCl}_{2} \mathrm{X} / \mathrm{MAO}$ at $50^{\circ} \mathrm{C}$

\begin{tabular}{lcccc}
\multicolumn{1}{c}{$\mathrm{X}$} & $\mathrm{Cl}$ & $\mathrm{OMe}$ & $\mathrm{OEt}$ & $\mathrm{OPr}^{\mathrm{i}}$ \\
\hline$[\mathrm{Ti}] / \mathrm{m} \mathrm{mol} \mathrm{L}^{-1}$ & 0.54 & 0.54 & 0.54 & 0.54 \\
{$[\mathrm{Al}] / \mathrm{mol} \mathrm{L}^{-1}$} & 0.96 & 0.96 & 0.96 & 0.96 \\
{$[\mathrm{St}] / \mathrm{mol} \mathrm{L}^{-1}$} & 2.5 & 2.5 & 2.5 & 2.5 \\
$\mathrm{Al} / \mathrm{Ti}\left(\mathrm{molar}^{\mathrm{c}} \mathrm{natio}\right)$ & 1750 & 1750 & 1750 & 1750 \\
$\mathrm{Time} / \mathrm{h}$ & 2 & 1 & 1 & 1 \\
Yield $/ \mathrm{g}$ & 0.390 & 0.455 & 0.430 & 0.385 \\
$\mathrm{~A}^{\mathrm{a}}\left(10^{6}\right)$ & 2.18 & 5.21 & 4.47 & 4.41 \\
$\mathrm{Syndio}^{\mathrm{b}} / \%$ & 86.5 & 90.5 & 96.1 & 95.4 \\
\hline
\end{tabular}

${ }^{\mathrm{a}} \mathrm{g} \mathrm{PS} / \mathrm{mol} \mathrm{Ti} \cdot \mathrm{mol} \mathrm{St} \cdot \mathrm{h} . \quad{ }^{\mathrm{b}} \mathrm{g}$ of 2-butanone insoluble polymer/g of bulk polymer.

\section{REFERENCES}

1. N. Ishihara, T. Seimiya, M. Kuramoto, and M. Uoi, Macromolecules, 19, 2464 (1986).

2. N. Ishihara, M. Kuramoto, and M. Uoi, Macromolecules, 21, 3356 (1988).

3. L. Oliva, C. Pellecchia, P. Cinquina, and A. Zambelli, Macromolecules, 22, 1642 (1989).

4. A. Zambelli, L. Oliva, and C. Pellecchia, Macromolecules, 22, 2129 (1989).

5. K. Soga and H. Nakatani, Macromolecules, 23, 957 (1989).

6. R. Mani and C. M. Burns, Macromolecules, 24, 5476 (1991).

7. J. C. W. Qian and Z. Salajka, J. Polym. Sci., Part A, Polym. Chem., 29, 1243, 1253 (1991).

8. J. C. W. Qian, Z. Salajka, and J. F. Dong, Macromolecules, 25, 3199 (1991).

9. M. L. Dias, A. Giarrusso, and L. Porri, Macromolecules, 26, 6664 (1993).

10. A. Zambelli, A. Grussi, M. Galimberti, and G. Perego, Makromol. Chem., Rapid Commun., 13, 269 (1992).

11. S. Moore, Modern Plastics International, (11), 22 (1992).

12. A. Kucht, H. Kucht, S. Barry, J. C. W. Chien, and M. D. Rausch, Organometallics, 12, 3075 (1993).

13. T. E. Ready, R. O. Day, J. C. W. Chien, and M. D. Rausch, Macromolecules, 26, 5822 (1993).

14. I. M. M. Fassing, D. Pletcher, and R. C. Whitby, Organomet. Chem., 470, 109 (1994).

15. R. D. Gorsich, J. Am. Chem. Soc., 82, 4211 (1960).

16. P. C. Bharara, J. Organomet. Chem., 121, 199 (1976).

17. J. C. W. Chien and B. P. Wang, J. Polym. Sci., Part A, Polym. Chem., 26, 3089 (1988).

18. N. Tomotsu, M. Kuramoto, M. Takeuchi, and H. Maezawa, Proceedings of Metallocenes '96, 1996, pp 183-184. 